\title{
Host cell and expression engineering for development of an E. coli ketoreductase catalyst: Enhancement of formate dehydrogenase activity for regeneration of $\mathrm{NADH}$
}

Katharina Mädje, Katharina Schmölzer, Bernd Nidetzky ${ }^{*}$ and Regina Kratzer ${ }^{*}$

\begin{abstract}
Background: Enzymatic NADH or NADPH-dependent reduction is a widely applied approach for the synthesis of optically active organic compounds. The overall biocatalytic conversion usually involves in situ regeneration of the expensive $N A D(P) H$. Oxidation of formate to carbon dioxide, catalyzed by formate dehydrogenase (EC 1.2.1.2; FDH), presents an almost ideal process solution for coenzyme regeneration that has been well established for NADH. Because isolated FDH is relatively unstable under a range of process conditions, whole cells often constitute the preferred form of the biocatalyst, combining the advantage of enzyme protection in the cellular environment with ease of enzyme production. However, the most prominent FDH used in biotransformations, the enzyme from the yeast Candida boidinii, is usually expressed in limiting amounts of activity in the prime host for whole cell biocatalysis, Escherichia coli. We therefore performed expression engineering with the aim of enhancing FDH activity in an E. coli ketoreductase catalyst. The benefit resulting from improved NADH regeneration capacity is demonstrated in two transformations of technological relevance: xylose conversion into xylitol, and synthesis of (S)-1-(2-chlorophenyl)ethanol from o-chloroacetophenone.
\end{abstract}

Results: As compared to individual expression of C. boidinii FDH in E. coli BL21 (DE3) that gave an intracellular enzyme activity of 400 units/9cDw, co-expression of the FDH with the ketoreductase (Candida tenuis xylose reductase; XR) resulted in a substantial decline in FDH activity. The remaining FDH activity of only $85 \mathrm{U} / \mathrm{g}_{\mathrm{cDw}}$ was strongly limiting the overall catalytic activity of the whole cell system. Combined effects from increase in FDH gene copy number, supply of rare tRNAs in a Rosetta strain of E. coli, dampened expression of the ketoreductase, and induction at low temperature $\left(18^{\circ} \mathrm{C}\right)$ brought up the FDH activity threefold to a level of $250 \mathrm{U} / \mathrm{g}_{\mathrm{CDw}}$ while reducing the XR activity by just 19\% (1140 U/g $\mathrm{CDw})$. The E. coli whole-cell catalyst optimized for intracellular FDH activity showed improved performance in the synthesis of (S)-1-(2-chlorophenyl)ethanol, reflected in a substantial, up to 5 -fold enhancement of productivity $\left(0.37 \mathrm{~g} / \mathrm{g}_{\mathrm{cDw}}\right)$ and yield (95\% based on $100 \mathrm{mM}$ ketone used) as compared to the reference catalyst. For xylitol production, the benefit of enhanced FDH expression was observed on productivity only after elimination of the mass transfer resistance caused by the cell membrane.

Conclusions: Expression engineering of C. boidinii FDH is an important strategy to optimize E. coli whole-cell reductase catalysts that employ intracellular formate oxidation for regeneration of $\mathrm{NADH}$. Increased FDH-activity was reflected by higher reduction yields of D-xylose and o-chloroacetophenone conversions provided that mass transfer limitations were overcome.

\footnotetext{
* Correspondence: bernd.nidetzky@tugraz.at; regina.kratzer@tugraz.at Institute of Biotechnology and Biochemical Engineering, Graz University of Technology (TUG), Petersgasse 12/1, A-8010 Graz, Austria
} 


\section{Background}

Enzymatic reductions are widely used for the preparation of single-isomer alcohols, amino acids and other fine chemicals. Reductases and dehydrogenases applied in biocatalysis usually utilize $\mathrm{NADP}(\mathrm{H})$ or $\mathrm{NAD}(\mathrm{H})$ as cofactors. The in situ recycling of the high priced and labile coenzymes remains a dictate of economic considerations. Candida boidinii formate dehydrogenase ( $\mathrm{CbFDH}$ ) has been employed as a workhorse for NADH-regeneration for decades and is used in one of the biggest processes of chiral synthesis, the production of tert-L-leucine [1,2]. The irreversible oxidation of formate to carbon dioxide pulls coupled reactions to complete conversion and therefore turned out as an optimal solution from a process point of view. Moreover principles of green chemistry are met by the low molecular weight co-substrate formate whose oxidation product $\mathrm{CO}_{2}$ is innocuous and evaporates from the reaction mixture. The general sensitivity of the known FDHs to organic solvents, however, prevents use of FDH in conversion of substrates with low water solubility. Recombinant E. coli strains co-expressing FDH and a reductase provide whole-cell biocatalysts that offer the advantage of protecting the enzyme against adverse medium effects in the cellular environment $[3,4]$. Whole cell bioreduction systems allow furthermore the production of the required activities for carbonyl reduction and coenzyme recycling by single bioreactor cultivation without further enzyme isolation. Efficiencies of whole cell reductions depend therefore on intracellular activities of the reductase and the cofactor recycling dehydrogenase. Previously reported $E$. coli whole cell catalysts based on $C b F D H$ were limited by low FDH activity in $E$. coli, especially under conditions of high reductase co-expression. $\mathrm{CbFDH}$ is therefore rarely used in whole cell systems [3-6] whereas many papers have been published on the corresponding conversions catalyzed by free enzymes.

The aim of the present work was to improve a previously developed whole cell biocatalyst based on Candida tenuis xylose reductase (CtXR) by boosting the intracellu-

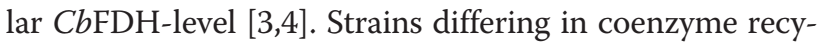
cling capacity were constructed and tested for productivities and yields in the production of two industrially relevant chemicals, xylitol and (S)-1-(2-chlorophenyl) ethanol. The exceptional substrate promiscuity of $C t \mathrm{XR}$ allowed the application of two reporter systems differing to a great extent in reactivity, polarity and toxicity. We thereby could show that limitations in whole cell reductions are strongly case-specific and substrate-dependent. Reduction yields obtained with whole cells as compared to cell free extracts permitted investigation of the role of mass transfer in the case of hydrophilic xylose whereas information on enzyme protection was provided when working with toxic $o$-chloroacetophenone.

\section{Results and Discussion}

E. coli has been known to accumulate recombinant protein to a level of up to $50 \%$ of the total cell protein [7]. Because of this very high protein production capacity, E. coli is the most widely used host organism in whole-cell biotransformations. However, the design of $E$. coli whole cell catalysts for ketone reduction must consider the complication that the activity of the ketoreductase should be balanced to the activity of the dehydrogenase applied for coenzyme regeneration. Finely tuned co-expression of the genes of interest is therefore required and standard solutions are currently not available to achieve this goal. We have shown in prior work that in $E$. coli cells expressing $C b F D H$ next to $C t \mathrm{XR}$, the activity of $\mathrm{CbFDH}$ was 4.8 -fold lower in comparison to the activity produced under $\mathrm{CbFDH}$-only expression conditions $[3,4]$. We have carried out this study with the aim of eliminating through the application of different strategies of cell and expression engineering the bottleneck of NADH regeneration in E. coli whole cells containing $\mathrm{CbFDH}$ and $C t \mathrm{XR}$. Gene copy number, promoter strength, codon usage, mRNA stability and translation velocity were factors taken into consideration.

\section{Optimization of $\mathrm{CbFDH}$ production under single-gene expression conditions}

When expressed from the previously described plasmid vector pBTac1, production of $C b F D H$ in E. coli JM109 resulted in an activity of $408 \mathrm{U} / \mathrm{g}_{\mathrm{CDW}}$ (Table 1, JM109 FDH). Based on a specific activity of $4.4 \mathrm{U} / \mathrm{mg}$ for purified $\mathrm{CbFDH}$, it was estimated from the protein content in the E. coli extract that $C b$ FDH had accumulated to about $18 \%$ of the total soluble protein. These numbers [8] serve as reference in the evaluation of the new $E$. coli constructed in this work.

Effects of gene copy number and promoter strength

The vector pBTac1 is used for protein expression of medium strength in E. coli. Target genes are cloned

\begin{tabular}{|c|c|c|}
\hline E coli strain & $\begin{array}{l}\text { CbFDH }\left(\mathrm{U} / \mathrm{g}_{\mathrm{CDW}}\right) \text { at } \\
25^{\circ} \mathrm{C}\end{array}$ & $\begin{array}{l}\mathrm{CbFDH}\left(\mathrm{U} / \mathrm{g}_{\mathrm{CDW}}\right) \text { at } \\
18^{\circ} \mathrm{C}\end{array}$ \\
\hline JM109_FDH & 408 (reference, [8]) & n.d. \\
\hline BL21_FDH & $402 \pm 38^{1}$ & 450 \\
\hline Star_FDH & 458 & 551 \\
\hline Rosetta_FDH & 445 & 614 \\
\hline$\overline{\text { BL21_XR_FDH }}$ & $85 \pm 12^{2}$ & $110 \pm 20^{2}$ \\
\hline 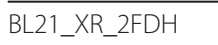 & $146 \pm 30^{1}$ & $186 \pm 30^{2}$ \\
\hline 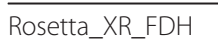 & $100 \pm 18^{1}$ & $138 \pm 23^{2}$ \\
\hline$\overline{\text { Rosetta_XR_2FDH }}$ & $202 \pm 21^{1}$ & $251 \pm 50^{2}$ \\
\hline
\end{tabular}

${ }^{1} n \geq 3 ;{ }^{2} n \geq 7 ;$ n.d. not determined. 
under control of the tac promoter/lac repressor system into the pBR322-derived vector. The moderate to high strength of the tac promoter is compromised by a low gene dosage of $15-20$ copies per cell [7]. The used strain JM109 is designed as cloning strain and generally not used as high level protein expression strain. E coli expression strains are deficient in two key proteases whereas JM109 lacks only one of these protease activities $[9,10]$. An increase in copy number and enhancement of promoter strength were considered as potentially useful strategies for improved $\mathrm{CbFDH}$ production. We chose pRSF-1b, an expression system for protein expression of up to $50 \%$ of the total $E$. coli protein due to a copy number of $>100$ and the strong T7lac promoter. The constructed pRSF-1b_FDH was transformed into BL21 (DE3), a host providing the T7 polymerase in trans and lacking key proteases $[9,10]$. Recombinant enzyme production in E. coli BL21 (DE3) gave an activity $\left(402 \mathrm{U} / \mathrm{g}_{\mathrm{CDW}}\right)$ essentially identical to that of the reference activity (Table 1 , JM109_FDH). These results suggested that the amount of transcript formed is not the main limitation in the expression of $C b F D H$ in $E$. coli. In prokaryotic cells, ribosomes translate mRNAs that are still being transcribed from DNA and thereby protect mRNAs from degradation. Fast mRNA synthesis by the T7 system, however, uncouples transcription from translation in E. coli and exposed mRNA is subject to enzymatic degradation [11]. We therefore studied the effect of improved mRNA stability.

\section{Effect of enhanced mRNA stability}

The average half-life of mRNA in $E$. coli at $37^{\circ} \mathrm{C}$ ranges from seconds to maximally $20 \mathrm{~min}$, and the expression rate depends directly on the inherent stability of the mRNA [12]. Increased mRNA lifetime might thus translate directly into enhanced $C b F D H$ production. We therefore expressed pRSF-1b_FDH in the RNaseE deficient E. coli strain BL21 star (DE3). RNaseE (rne 131) has been reported to be a major source of mRNA degradation in E. coli [9]. Functional expression of $\mathrm{CbFDH}$ was improved by about $14 \%$ in E. coli BL21 star (DE3) as compared to the reference (Table 1, JM109_FDH).

\section{Effect of providing rare tRNAs}

Codon usage bias is a frequent problem encountered in the expression of eukaryotic proteins in E. coli [13]. Sequence analysis of $C b F D H$ revealed 13 especially rare triplets encoding arginine (agg, aga) and two rare isoleucine codons (ata) [14]. The pRSF-1b_FDH plasmid was therefore transformed into E. coli Rosetta 2 (DE3), a derivative of BL21 (DE3) that was specially designed to enhance recombinant production of eukaryotic proteins. Rosetta strains supply tRNAs for six codons that are rarely used in $E$. coli and include the above mentioned arginine and isoleucine codons. Using expression from pRSF1b_FDH in E. coli Rosetta 2 (DE3), we could enhance the activity of $C b F D H$ by $11 \%$ as compared to the reference (Table 1).

\section{Effect of induction conditions}

It has been known that a decrease in induction temperature can generate positive effects on recombinant protein production, often resulting from a generally lowered expression rate or change in the relative rates of protein folding and aggregation [9]. We examined $\mathrm{CbFDH}$ production in E. coli strains BL21 (DE3), BL21 star (DE3) and Rosetta 2 (DE3), using $18^{\circ} \mathrm{C}$ instead of $25^{\circ} \mathrm{C}$ during the induction phase. Table 1 shows that FDH-activities were raised between 12 and $38 \%$ by the application of a lower induction temperature. The highest $C b F D H$ activity of $614 \mathrm{U} / \mathrm{g}_{\mathrm{CDW}}$ was obtained by using a host strain with improved capability of handling rare codons and induction at $18^{\circ} \mathrm{C}$ (Table 1). Optimization of singleexpression led to a 1.5-fold improvement in $\mathrm{CbFDH}$ activity, equal to $28 \%$ of the total soluble protein in the E. coli extract.

\section{Co-expression of $\mathrm{CbFDH}$ and $\mathrm{CtXR}$ \\ Expression of two genes from $P E T$-Duet vector}

We have previously described the plasmid vector pETDuet_XR_FDH for co-expression of $C b F D H$ and $C t X R$ [3]. This vector was derived from a pET-Duet-1 plasmid and contained the gene of $C t \mathrm{XR}$ and $\mathrm{CbFDH}$ inserted in its first and second multiple cloning site (MCS1, MCS2), respectively. The order of placement of the two genes reflected the notion that the second inserted gene is generally expressed more strongly than the gene inserted first. MCS1 is missing a T7 terminator which leads to transcriptional read-through that destabilizes corresponding mRNAs $[9,12]$. Enzyme production was done in E. coli BL21 (DE3), and the XR activity of 1804 $\mathrm{U} / \mathrm{g}_{\mathrm{CDW}}$ was comparable to the activity $\left(\mathrm{U} / \mathrm{g}_{\mathrm{CDW}}\right)$ obtained under single gene expression conditions using a pET11a plasmid vector in E. coli BL21 (DE3) [15]. The FDH activity, by contrast, was just about one-fifth ( $85 \mathrm{U} / \mathrm{g}_{\mathrm{CDW}}$ ) of the activity obtained under single gene expression conditions using pBTac1 in E. coli JM109 (Table 1, strain BL21_XR_FDH) [8].

Equal gene copy number and promoter strength provided by pET-Duet-1 led to imbalanced reductase and dehydrogenase activities. Expression of functional CtXR in BL21_XR_FDH accounts for $30 \%$ of soluble protein in E. coli, 7.7-fold as compared to CbFDH. To improve FDH activity under conditions of $C b F D H$ and $C t \mathrm{XR}$ co-expression, we tried to repress $C t \mathrm{XR}$ expression by gene copy number variations. Moreover, the host Rosetta 2 (DE3) assured provision of rare codon tRNAs and culture conditions found to be useful for FDH production under single gene expression conditions were applied. 


\section{Expression of two genes from two vectors}

The pBR322-derived replicon of pET-Duet-1 determines a copy number of approximately 40 per cell [16]. The vector carries two T7lac promoters preceding MCS1 and MCS2 and an ampicillin resistance gene. Co-expression from multiple plasmids requires compatible replicons and different antibiotic resistances [16]. The newly constructed pRSF_FDH contains a RSF1030 replicon and a kanamycin resistance, both compatible with pET-Duet-1. An increase in $\mathrm{CbFDH}$ gene copy number from $\sim 40$ to $>140$ by cotransformation of BL21 (DE3) with pETDuet_XR_FDH and pRSF_FDH resulted in a two-fold increased FDHactivity from 85 to $146 \mathrm{U} / \mathrm{g}_{\mathrm{CDW}}$ (Table 1 , strain BL21_XR_ 2FDH). Transformation of Rosetta 2 (DE3) harbouring the co-expression plasmid with pRSF_FDH resulted in $202 \mathrm{U} / \mathrm{g}_{\mathrm{CDW}}$. A decrease in induction temperature from 25 to $18^{\circ} \mathrm{C}$ further improved $\mathrm{CbFDH}$ activity in the cell free raw extract to $251 \mathrm{U} / \mathrm{g}_{\mathrm{CDW}}$ (Table 1, strain Rosetta $\left.\mathrm{XR} \_2 \mathrm{FDH}\right)$. This is equal to a 3-fold increase in functional FDH expression with a concomitant $C t \mathrm{XR}$ activity reduction from 1406 to $1140 \mathrm{U} / \mathrm{g}_{\mathrm{CDW}}$ (Table 2).

The obtained $\mathrm{CbFDH}$ activity of $500 \mathrm{U} / \mathrm{g}_{\text {protein }}$ is, to the best of our knowledge, the highest activity reported for coexpression strains so far $[5,17]$. Weckbecker et al. expressed $\mathrm{CbFDH}$ and three further genes from compatible duet-plasmids. The alcohol dehydrogenase and $\mathrm{CbFDH}$ were cloned into the first and second cloning site of the low copy number plasmid pACYCDuet-1. The host BL21 (DE3) was co-transformed with pETDuet-1 carrying the two subunits of the transhydrogenase. The obtained FDH activity of $210 \mathrm{U} / \mathrm{g}_{\text {protein }}$ seems relatively high under induction conditions for several reasons [5]. First, the low copy number of the $C b F D H$ gene, second the co-expression of three further genes and third, the induction temperature of $37^{\circ} \mathrm{C}$. However, the three co-expressed genes are of prokaryotic origin (E. coli transhydrogenase, Lactobacillus kefir alcohol dehydrogenase) whereas eukaryotic genes are co-expressed in the present study. The combined expression of $\mathrm{CbFDH}$ and $C t \mathrm{XR}$ in Rosetta 2 (DE3) adds up to $31 \%$ of soluble $E$. coli protein. Arg codons used in $C b \mathrm{FDH}$ and $C t \mathrm{XR}$ (aga, agg; [14]) count among the specifically rare codons in $E$. coli and are $\sim 10$-times more frequently used as compared to its natural occurrence in
E. coli. $\mathrm{CbFDH}$ carries furthermore a tandem rare Argcodon double repeat (Arg210, Arg211; [14]). Ribosome stalling at the tandem rare codon double repeat might account for low $C b F D H$ expression at concurrent high $C t \mathrm{XR}$ production [9]. $\mathrm{CbFDH}$ co-expression with $C t \mathrm{XR}$ requires a throttling in protein production velocity most probably owing to rare arg-codon dependence of both genes.

The high complexity of protein co-expression complicates the correlation of expression parameter to enzyme activity. We therefore performed a factorial design to figure out the most relevant variables influencing $\mathrm{CbFDH}$ activity in co-expression strains. $\mathrm{CbFDH}$ activities denoted in Table 1 served as response variable of a $2^{3}$ factorial design using type of host, gene copy number and induction temperature as independent variables. All three factors turned out as significantly influencing $\mathrm{C} b \mathrm{FDH}$ activity by means of statistics. Gene copy numbers were most important in balancing $\mathrm{CbFDH}$ and $\mathrm{CtXR}$ co-expression. Exchange of BL21 by Rosetta 2 and a decrease in induction temperature from 25 to $18^{\circ} \mathrm{C}$ showed comparable effects on $\mathrm{C} b \mathrm{FDH}$ activity. Effects of interactions between factors are of minor importance to the $C b F D H$ activity. (Pareto chart of main effects and interactions between factors are shown in the Additional file 1.) Bioreductions of $\mathrm{D}$-xylose and $o$-chloroacetophenone were used to study the effect of increased intracellular FDH-activity on initial rates and productivities.

\section{Bioreductions}

CtXR converts its natural substrate $\mathrm{D}$-xylose and xenobiotic $o$-chloroacetophenone with specific activities of 12 and $4.4 \mathrm{U} / \mathrm{mg}$, respectively. Sugar-bioreduction constitutes a completely different problem in whole cell biocatalysis as compared to reduction of aromatic ketones. The two main problems in whole cell biocatalysis - biocatalyst stability and substrate availability - are differentially affected by substrates with opposed polarities [3,4]. Whole cell reductions of hydrophilic xylose and hydrophobic $o$-chloroacetophenone were used to study the effect of increased FDH-activity under contrary conditions. The corresponding products, xylitol and (S)-1-(2-chlorophenyl)ethanol, are used in food-processing and pharmaceutical industry.

Table 2 Yields of o-chloroacetophenone reductions catalyzed by E. coli whole-cell biocatalysts variable in XR and FDH activities

\begin{tabular}{|c|c|c|c|c|c|c|}
\hline$E$ coli & $\mathrm{pH}$ & XR $\left(\mathrm{U} / \mathrm{g}_{\mathrm{CDW}}\right)$ & $\mathrm{FDH}\left(\mathrm{U} / \mathrm{g}_{\mathrm{CDW}}\right)$ & Substrate $(\mathrm{mM})$ & 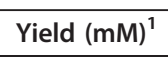 & Yield $(\mathrm{mM})^{1,2}$ \\
\hline BL21_XR_FDH & 7.5 & 1406 & 110 & 100 & 19 & 46 \\
\hline Rosetta_XR_2FDH & 7.5 & 1140 & 251 & 100 & 35 & 67 \\
\hline 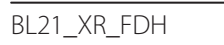 & 6.2 & 2226 & 48 & 100 & 27 & 78 \\
\hline Rosetta_XR_2FDH & 6.2 & 2024 & 189 & 100 & 63 & 95 \\
\hline
\end{tabular}

${ }^{1}$ Determined for a reaction time of $8 \mathrm{~h} .{ }^{2}$ Additives: $36 \mu \mathrm{M}$ Polymyxin B sulphate and $500 \mu \mathrm{M} \mathrm{NAD}$. 
The alternative food sweetener xylitol is produced in ton scale and chiral 1-(2-chlorophenyl)ethanols are key intermediates in the synthesis of a novel class of chemotherapeutic substances (PLK1 kinase inhibitors; [18-20]).

\section{Xylitol production}

We compared the strains BL21_XR_FDH and Rosetta_XR_2FDH in whole cell reductions of $250 \mathrm{mM}$ Dxylose (Figure 1). Time courses of xylitol formation were, within the experimental error, identical for both strains. Initial rates $\left(r_{\mathrm{s}}\right)$ of $\sim 50 \mathrm{U} / \mathrm{g}_{\mathrm{CDW}}$ were calculated from the linear parts of time courses (0-30 min). After $24 \mathrm{~h}$ product yields of $55 \%$ with productivities of $2.0 \mathrm{~g}_{\text {product }} / \mathrm{g}_{\mathrm{CDW}}$ were obtained. We and others have previously shown that rates in whole cell biocatalysis are governed by the activity levels of enzymes and the substrate availability in the cell $[3,4,21,22]$. Similar xylose reduction rates for cells differing 2 -fold in cofactor recycling activity suggest a main obstacle in substrate and/or co-substrate import into the cell. Kaup et al. used an E. coli whole cell catalyst co-expressing mannitol dehydrogenase and a bacterial FDH for the reduction of fructose. Mannitol yields were limited by the fructose uptake into the cell. Removal of mass transfer resistance by the co-expression of a fructose transporter led to a 14-fold increase in yields [21]. Protection of enzymes in the united cell structure is not required for the conversion of bio-compatible sugar substrates. We therefore repeated the bioreductions of xylose with disrupted cells (crude cell extracts) under otherwise identical conditions. We obtained $r_{\mathrm{s}}$ for xylitol formation of $125 \mathrm{U} / \mathrm{g}_{\mathrm{CDW}}$ and 263 $\mathrm{U} / \mathrm{g}_{\mathrm{CDW}}$ for BL21_XR_FDH and Rosetta_XR_2FDH, respectively (Figure 1). The 2.5 and 5 -fold increases in $r_{\mathrm{s}}$

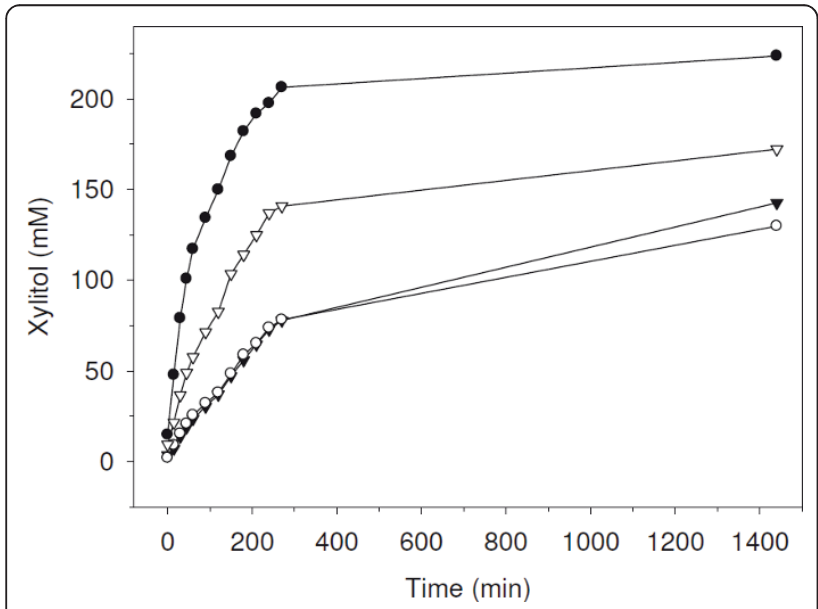

Figure 1 Bioreductions of D-xylose catalyzed by whole cells and crude cell extracts of $E$. coli strains BL21_XR_FDH and Rosetta_XR_2FDH. Type of catalyst is indicated by symbols: • Rosetta_XR_2FDH crude extract; O Rosetta_XR_2FDH whole-cell catalyst; $\nabla$ BL21_XR_FDH crude extract; $\mathbf{\nabla}$ BL21_XR_FDH whole-cell catalyst. Reaction conditions: D-xylose $(250 \mathrm{mM})$, sodium formate (300 mM), cells $\left(10 \mathrm{~g}_{\mathrm{CDW}} / \mathrm{L}\right), 30^{\circ} \mathrm{C}$. obtained with the crude cell extracts as compared to whole cells identify substrate import into the cell as main limiting factor. Initial rates agree well with FDH-activities determined photometrically in the cell free crude extracts of BL21_XR_FDH $\left(110 \mathrm{U} / \mathrm{g}_{\mathrm{cdw}}\right)$ and Rosetta_XR_2FDH $\left(251 \mathrm{U} / \mathrm{g}_{\mathrm{cdw}}\right)$ (Table 1 ; induction at $\left.18^{\circ} \mathrm{C}\right)$. Virtually identical $r_{\mathrm{s}}$ values calculated from bioreductions and photometric FDH assays unmask the cofactor recycling rate as second limiting factor. The 2 -fold higher initial rate and higher conversion obtained with the FDH optimized strain directly reflects the FDH-expression level in the cell which in turn rules out substrate or product inhibitions under reaction conditions. The combination of mass transfer relief and cofactor recycling improvement led to a conversion of $>90 \%$ with a productivity of $3.4 \mathrm{~g}_{\text {product }} / \mathrm{g}_{\mathrm{CDW}}$.

\section{(S)-1-(2-chlorophenyl)ethanol production}

We compared E. coli BL21_XR_FDH and the FDH-optimized strain Rosetta_XR_2FDH in whole cell reductions of $100 \mathrm{mM} o$-chloroacetophenone. Product concentrations obtained with BL21_XR_FDH and Rosetta_XR_2FDH yielded 19 and $35 \mathrm{mM}(S)$-1-(2-chlorophenyl)ethanol, respectively (ee > 99.9; Table 2). Reduction of hydrophobic $o$-chloroacetophenone was therefore 1.8-fold improved by the 2.3-fold higher intracellular FDH activity of Rosetta_XR_2FDH (Table 2). Standard reactions and activity measurements were carried out in potassium phosphate buffer at $\mathrm{pH} 7.5$; isolated xylose reductase however shows $\sim 70 \%$ higher activities at $\mathrm{pH}$ 6.2. By lowering the reaction $\mathrm{pH}$ from 7.5 to 6.2 product yields increased $40 \%$ for the initial strain and $80 \%$ for the FDH optimized strain (Table 2). Higher reduction yields obtained with the FDHoptimized strain or at a more acidic reaction $\mathrm{pH}$ strongly indicate a permeabilizing effect of $o$-chloroacetophenone and its reduction product on $E$. coli cells. We have previously shown that the high toxicity of $o$-chloroacetophenone towards biocatalyts restricts the time of $E$. coli whole cell reductions to maximally $\sim 5 \mathrm{~h}$ due to fast catalyst deactivation [4]. Mass transfer limitations on the one hand and substrate toxicity on the other hand requires cautious balancing of cell permeabilization. We used Polymyxin B sulphate to gently permeabilize the cell envelope and thereby further accelerate the uptake of ketone and formate. Reduction of mass transfer limitation over the cell membrane was reflected by increases in product concentrations to 78 and $95 \mathrm{mM}$ obtained with BL21_XR_FDH and Rosetta_XR_2FDH, respectively. The enantiomeric excess of the product $(S)$-1-(2-chlorophenyl)ethanol was $>99.9 \%$ in all experiments.

(S)-1-(2-chlorophenyl)ethanol formation was elevated by increasing intracellular FDH- or XR-activities. Product yield sensitivity for both enzyme activities suggests similar specific activities under process conditions. Reductase activities for $o$-chloroacetophenone are 2.7fold reduced as compared to xylose activities in Table 2. 
Ketone reductase activity was determined at $10 \mathrm{mM}$ substrate, which is the solubility limit of $o$-chloroacetophenone in phosphate buffer and roughly reflects the available substrate at $100 \mathrm{mM}$. Formate concentrations in FDH-activity assays and in whole cell reductions were $\geq 10$-fold $K_{\text {formate }}(15 \mathrm{mM}$ [8]) and saturating. The formate concentration in whole cell reductions was adjusted to $150 \mathrm{mM}, 50 \mathrm{mM}$ excess regarding the ketone concentration. Substrate availability seems to govern the specific activity of the whole cell catalyst not only in the case of xylose but also with $o$-chloroacetophenone. A limitation of substrate and co-substrate in the cell effects the activity of whole cell catalysts differentially, because XR-activity depends linearly on the

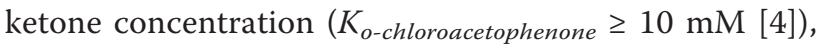
whereas a formate concentration of $150 \mathrm{mM}$ is 10 -fold the $K_{\text {formate. }}$.

\section{Conclusions}

A particular challenge in the development of 'designer bugs' based on $C b F D H$ is the low level of intracellular FDH in co-expression strains. Especially high overexpression of $C t \mathrm{XR}$ restricted FDH co-expression to $85 \mathrm{U} / \mathrm{g}_{\mathrm{CDW}}$. We used expression engineering to fine tune formate dehydrogenase and reductase activity levels in E. coli. Our strategy was to co-express $C t \mathrm{XR}$ and $C b F \mathrm{FH}$ based on the same inducible promoter for both genes but with different gene copy numbers. We furthermore used an E. coli host optimized for the expression of eukaryotic genes by supplying tRNAs for six codons that are rarely used in E. coli. Activities of $C t \mathrm{XR}$ and $C b F D H$ were - after optimization of induction - $1140 \mathrm{U} / \mathrm{g}_{\mathrm{CDW}}$ and $251 \mathrm{U} / \mathrm{g}_{\mathrm{CDW}}$, respectively. Improved $\mathrm{FDH}$-activity resulted in full conversion of $250 \mathrm{mM} \mathrm{D}$-xylose and $100 \mathrm{mM} o$-chloroacetophenone provided that mass transfer limitations are negligible. Full exploitation of higher FDH-activities required elimination of cell wall obstacle in the reduction of D-xylose. Hydrophobic $o$-chloroacetophenonen and (S)-1-(2-chlorophenyl) ethanol that destroy free $C t \mathrm{XR}$ and $C b F D H$ within minutes [4], permeabilize the cell membrane and thereby facilitate substrate uptake. Further permeabilzation was done with the antibiotic Polymyxin B sulphate. The conversion of toxic, hydrophobic compounds by whole cells requires additional reaction engineering to protect the catalyst. A convenient method is the in situ extraction of hydrophobic compounds onto or into non-polar, second phases. Doig et al. (2002) have previously shown that the inhibitory effect of the lactone substrate bicycle[3.3.0]hept-2-en6-one was overcome by a combination of substrate feeding and in situ substrate supply [23]. Strategies to overcome low cell activities and stabilities under process conditions comprise therefore expression engineering, elimination of mass transfer resistances and protection of the catalyst.

\section{Methods}

\section{Chemicals}

NADH (sodium salt; $\geq 98 \%$ pure), $\mathrm{NAD}^{+}$(free acid; $\geq 97.5 \%$ pure), D-xylose, and ampicillin were purchased at Roth (Karlsruhe, Germany). Sodium formate, Polymyxin B sulphate, kanamycin, chloramphenicol, and $o$-chloroacetophenone were obtained from Sigma-Aldrich (Vienna, Austria). B-Per ${ }^{\circledR}$ Reagent was from Pierce (Rockford, IL, USA) and 1-(2-chlorophenyl)ethanol from Alfa Aesar (Karlsruhe, Germany). Pfu DNA polymerase was from Promega (Madison, WI, USA). dNTPs, T4 DNA ligase and restriction enzymes were obtained from MBI Fermentas (Flamborough, ON, Canada). Primers were synthesized by Invitrogen (Carlsbad, California, USA). Vectors pRSF$1 \mathrm{~b}$ and pETDuet-1 were purchased at Novagen (VWR International $\mathrm{GmbH}$, Vienna Austria). All other chemicals were from Sigma-Aldrich/Fluka or Roth, and were of the highest purity available.

\section{Strains and plasmids}

The E. coli strains used were JM109 from Promega (Madison, WI, USA), BL21 (DE3) and Rosetta 2 (DE3) from Novagen (VWR International GmbH, Vienna, Austria) and BL21 star (DE3) from Invitrogen (Carlsbad, California, USA). All DNA manipulations and bacterial transformations were carried out according to standard protocols. The construction of the E. coli BL21 (DE3) (BL21_XR_FDH) harbouring CtXR and CbFDH genes on a pETDuet-1 vector (pETDuet_XR_FDH) was described elsewhere [3]. The CbFDH gene was amplified from pETDuet_XR_FDH by a PCR using Pfu DNA polymerase and primers providing PagI (compatible ends to NcoI) and AvrII restriction sites.

Forward primer: 5'- GGTGGTTCATGAAGATCGTTTTAG- 3 '

Reverse primer: 5'- GTAAACACGATAAGAAATAACCTAGGGGTGGT - 3'

The $C b$ FDH gene was cloned into the multiple cloning site of pRSF-1b (NcoI, AvrII) prior to verification of correct integration by sequencing (pRSF_FDH). Bacterial transformation followed a standard electroporation protocol. For single-expression of $\mathrm{CbFDH}$, pRSF_FDH was transformed into BL21 (DE3), BL21 (DE3) star and Rosetta 2 (DE3), for co-expression these strains were co-transformed with pETDuet_XR_FDH. Constructs are summarized in Table 3.

\section{Cultivation of strains}

E. coli strains were grown in $1000 \mathrm{~mL}$ baffled shaken flasks containing $200 \mathrm{~mL}$ of LB media supplemented with antibiotics according to Table 3. Flasks were shaken at $130 \mathrm{rpm}$ and $37^{\circ} \mathrm{C}$ in a Certomat ${ }^{\circledR}$ BS-1 incubator from Sartorius. At an optical density of $1.1( \pm 10 \%)$ 
Table 3 E. coli expression strains addressed in this study

\begin{tabular}{lllll}
\hline E. coli host & Plasmid & Enzyme & Antibiotic & Abbreviation \\
\hline JM109 & pBTac1 & CbFDH & Amp $^{1}$ & JM109_FDH [8] \\
\hline BL21 (DE3) & pRSF-1b & CbFDH & Kan $^{2}$ & BL21_FDH \\
\hline Rosetta 2 (DE3) & pRSF-1b & CbFDH & Cam $^{3}$, Kan & Rosetta_FDH \\
\hline BL21 star (DE3) & pRSF-1b & CbFDH & Kan & Star_FDH \\
\hline BL21 (DE3) & pETDuet-1 & CtXR, CbFDH & Amp & BL21_XR_FDH \\
\hline BL21 (DE3) & $\begin{array}{l}\text { pETDuet-1 } \\
\text { pRSF-1b }\end{array}$ & CtXR, CbFDH; CbFDH & Amp, Kan & BL21_XR_2FDH \\
\hline Rosetta 2 (DE3) & pETDuet-1 & CtXR, CbFDH & Cam, Amp & Rosetta_XR_FDH \\
\hline Rosetta 2 (DE3) & $\begin{array}{l}\text { pETDuet-1 } \\
\text { pRSF-1b }\end{array}$ & CtXR, CbFDH; CbFDH & Cam, Amp, Kan & Rosetta_XR_2FDH \\
\hline BL21 star (DE3) & pETDuet-1 & PRSF-1b & A XXR, CbFDH; CbFDH & Star_XR_2FDH \\
\hline
\end{tabular}

${ }^{1}$ Ampicillin $115 \mathrm{mg} / \mathrm{Li}^{2}$ kanamycin $50 \mathrm{mg} / \mathrm{Li}{ }^{3}$ chloramphenicol $34 \mathrm{mg} / \mathrm{L}$.

cultures were cooled to 25 or $18^{\circ} \mathrm{C}$ and protein production was induced by addition of $250 \mu \mathrm{M}$ isopropyl- $\beta$-Dthiogalactopyranosid (IPTG). After $20 \mathrm{~h}$ of cultivation, cells were harvested by centrifugation. Samples were taken and the B-Per ${ }^{\circledR}$ cell lysis reagent was used for protein extraction prior to enzyme activity measurements.

\section{Enzyme activity measurements in the cell-free extract}

Reductase and dehydrogenase activities were assayed spectrophotometrically at $340 \mathrm{~nm}$ by monitoring the reduction or oxidation of $\mathrm{NAD}(\mathrm{H})$ over a time period of 5 minutes (rates of $0.05-0.10 \Delta \mathrm{A} / \mathrm{min}$ ). One unit of enzyme activity refers to $1 \mu \mathrm{mol}$ of $\mathrm{NAD}(\mathrm{H})$ consumed or formed per minute. All activity measurements were performed with a Beckman DU-800 spectrophotometer thermostated at $25^{\circ} \mathrm{C}$. Xylose reductase activity was either determined with the native substrate $\mathrm{D}$-xylose $(700 \mathrm{mM})$ or with $o$-chloroacetophenone $(10 \mathrm{mM})$. Reactions were started with addition of NADH in a final concentration of $310 \mu \mathrm{M}$. The assay for formate dehydrogenase activity contained $200 \mathrm{mM}$ sodium formate and the reaction started with the addition of $2 \mathrm{mM} \mathrm{NAD}^{+}$. Activity assays were performed in $100 \mathrm{mM}$ potassium phosphate buffer, $\mathrm{pH} 7.5$ or 6.2. Five \% ethanol was added to the buffer to enhance the solubility of $o$-chloroacetophenone. Measured rates were corrected for the appropriate blank readings accounting for non-specific oxidation or reduction of $\mathrm{NAD}(\mathrm{P})(\mathrm{H})$ by the cell extracts.

\section{Whole-cell bioreductions}

Experiments were carried out at $30^{\circ} \mathrm{C}$ on an end-overend rotator (SB3 from Stuart) at $30 \mathrm{rpm}$.

\section{D-Xylose}

Biomass of each strain was divided into halves. One half of the cell material was diluted to $10 \mathrm{~g}_{\mathrm{CDW}} / \mathrm{L}$ with $100 \mathrm{mM}$ potassium phosphate buffer $\mathrm{pH} 7.5 .10 \mathrm{~mL}$ of the cell suspension were filled into a $15 \mathrm{~mL}$ Sarstedt tube with
$300 \mathrm{mM}$ co-substrate sodium formate added. The second half of the cells were disrupted by three passages through a French press (American Instrument Company, Silver Springs, Maryland, USA) operated at an applied pressure of 1000 psi. The crude cell extracts obtained were diluted with $100 \mathrm{mM}$ potassium phosphate buffer, $\mathrm{pH} 7.5$ to a concentration equivalent to $10 \mathrm{~g}_{\mathrm{CDW}} / \mathrm{L}$. After ultra-centrifugation, $10 \mathrm{~mL}$ of supernatant was transferred into a $15 \mathrm{~mL}$ Sarstedt tube and supplemented with $300 \mathrm{mM}$ sodium formate and $500 \mu \mathrm{M} \mathrm{NAD}{ }^{+}$. Conversions were started by the addition of $250 \mathrm{mM}$ xylose. $200 \mu \mathrm{L}$ samples were taken over time and the reaction was stopped after $24 \mathrm{~h}$ by the addition of ethanol in a 1:1 (v/v) ratio. Centrifugation separated the biomass and the product-containing supernatant was prepared for high performance liquid chromatography (HPLC).

\section{o-Chloroacetophenone}

E. coli cells were diluted to a concentration of $40 \mathrm{~g}_{\mathrm{CDW}} / \mathrm{L}$ with $100 \mathrm{mM}$ potassium phosphate buffer of either $\mathrm{pH} 7.5$ or 6.2. The co-substrate sodium formate was added in a concentration of $150 \mathrm{mM}, 50 \mathrm{mM}$ excess as compared to the substrate $o$-chloroacetophenone. Reactions were started by the addition of $o$-chloroacetophenone which was pre-dissolved in ethanol to enhance its solubility. Final ethanol concentrations were $5 \%$. Polymyxin B sulphate and $\mathrm{NAD}^{+}$were added in concentrations of 36 and $500 \mu \mathrm{M}$, respectively, to the reaction mix. Total reaction volumes were $1 \mathrm{~mL}$ and bioreductions of $o$-chloroacetophenone were performed in $2 \mathrm{~mL}$ Eppendorf tubes. After eight hours reactions were stopped by the addition of ethanol in a 1:1 (v/v) ratio. Cells were then separated by centrifugation and the supernatant was analyzed by chiral HPLC.

\section{Analytical methods}

HPLC-analysis of whole-cell reductions was performed on a LaChrom HPLC system (Merck-Hitachi) equipped 
with an L-7400 UV-detector (210 nm), a Merck L-7490 RI detector, and a thermo-stated column oven.

\section{D-Xylose}

Samples were analysed on an Aminex HPX-87H column (Bio Rad Laboratories, Vienna, Austria) using sulphuric acid $\left(5 \mathrm{mM} \mathrm{H}_{2} \mathrm{SO}_{4}\right.$ ) as eluent at a flow rate of $0.6 \mathrm{~mL} / \mathrm{min}$ and a temperature of $65^{\circ} \mathrm{C}$. For xylitol peak identification and quantification authentic standards with known concentrations were measured. Reported yields of xylitol product are always from analytical data, product isolation was beyond the scope of this study.

\section{o-Chloroacetophenone}

Samples were analysed on a reversed phase CHIRALPAK AD-RH column from Daicel (VWR International, Vienna, Austria) using an acetonitrile-water mixture $(20: 80 \mathrm{v} / \mathrm{v})$ at a flow rate of $0.5 \mathrm{~mL} / \mathrm{min}$ and a column temperature of $40^{\circ} \mathrm{C}$. For alcohol peak identification standards with known concentrations were measured. Reported product yields are always from analytical data.

\section{Additional material}

Additional file 1: Factorial design. CbFDH activity measured in the cellfree extract was specified as response variable of a $2^{3}$ factorial design. Type of host (A), number of plasmids (B) and induction temperature (C) were chosen as experimental factors.

\section{Acknowledgements}

The financial support from the Austrian Science Fund (FWF; Hertha-Firnberg grant T350-B09) is gratefully acknowledged.

\section{Authors' contributions}

KM and KS performed the experiments and analyzed the experimental data. KM was involved in experimental design and manuscript preparation. BN has made substantial contributions to conception, interpretation of data and revised the manuscript. RK designed the experiments, interpreted the results and drafted the manuscript. All authors read and approved the final manuscript.

\section{Competing interests}

The authors declare that they have no competing interests.

Received: 10 August 2011 Accepted: 11 January 2012

Published: 11 January 2012

\section{References}

1. Tishkov VI, Popov VO: Protein engineering of formate dehydrogenase. Biomol Eng 2006, 23:89-110.

2. Bommarius AS, Schwarm M, Stingl K, Kottenhahn M, Huthmacher K, Drauz K: Synthesis and use of enantiometrically pure tert-leucine. Tetrahedron Asymmetry 1995, 6:2851-2888.

3. Kratzer R, Pukl M, Egger S, Nidetzky B: Whole-cell bioreduction of aromatic a-keto esters using Candida tenuis xylose reductase and Candida boidinii formate dehydrogenase co-expressed in Escherichia coli. Microb Cell Fact 2008, 7:37-48

4. Kratzer R, Pukl M, Egger S, Vogl M, Brecker L, Nidetzky B: Enzyme identification and development of a whole-cell biotransformation for asymmetric reduction of o-chloroacetophenone. Biotech Bioeng 2011 101:1094-1101.

5. Weckbecker A, Hummel W: Improved synthesis of chiral alcohols with Escherichia coli cells co-expressing pyridine nucleotide transhydrogenase, $\mathrm{NADP}^{+}$-dependent alcohol dehydrogenase and NAD ${ }^{+}$-dependent formate dehydrogenase. Biotechnol Letters 2004, 26:1739-1744.

6. Gröger $H$, May $O$, Werner $H$, Menzel A, Altenbuchner J: A 'secondgeneration process' for the synthesis of L-neopentylglycine: Asymmetric reductive amination using a recombinant whole cell catalyst. Org Process Res Dev 2006, 10:666-669.

7. Baneyx F: Recombinant protein expression in Escherichia coli. Curr Opin Biotechnol 1999, 10:411-421.

8. Krahulec S, Armao GC, Weber H, Nidetzky B: Characterization of recombinant Aspergillus fumigatus mannitol-1-phosphate 5dehydrogenase and its application for the stereoselective synthesis of protio and deuterio forms of D-mannitol 1-phosphate. Carbohydr Res 2008, 9:1414-1423.

9. Sørensen HP, Mortensen KK: Advanced genetic strategies for recombinant protein expression in Escherichia coli. J Biotechnol 2005, 115:113-128.

10. ,E. coli genotypes from http://openwetware.org/wiki/E._coli_genotypes.

11. lost I, Dreyfus M: The stability of Escherichia coli lacZ mRNA depends upon the simultaneity of its synthesis and translation. EMBO J 1995, 14:3252-3261.

12. Régnier $P$, Arraiano CM: Degradation of mRNA in bacteria: Emergence of ubiquitous features. BioEssay 2000, 22:235-244.

13. Makrides SC: Strategies for achieving high-level expression of genes in Escherichia coli. Microbiol Mol Biol Rev 1996, 60:512-538.

14. Rare Codon Calculator (RaCC) from http://nih.mbi.ucla.edu/ at the UCLA.

15. Häcker B, Habenicht A, Kiess M, Mattes R: Xylose utilisation: Cloning and characterisation of the xylose reductase from Candida tenuis. Biol Chem 1999, 12:1395-1403.

16. Novy R, Yaeger K, Held D, Mierendorf R: Coexpression of multiple target proteins in E. coli. inNovations 2002, 15:2-6.

17. Menzel A, Werner H, Altenbucher J, Gröger H: From enzymes to "designer bugs" in reductive amination: A new process for the synthesis of L-tertleucine using a whole cell-catalyst. Eng Life Sci 2004, 4:573-576.

18. Santamaria A, Neef $R$, Eberspächer U, Eis K, Husemann M, Mumberg D, Prechtl S, Schulze V, Siemeister G, Wortmann L, Barr FA, Nigg EA: Use of the novel Plk1 inhibitor ZK-thiazolidinone to elucidate functions of Plk1 in early and late stages of mitosis. Mol Biol Cell 2007, 18:4024-4036.

19. Sato $Y$, Onozaki $Y$, Sugimoto $T$, Kurihara $H$, Kamijo $K$, Kadowaki $C$, Tsujino $T$, Watanabe A, Otsuki S, Mitsuya M, lida M, Haze K, Machida T, Nakatsuru Y, Komatani H, Kotani H, Iwasawa Y: Imidazopyridine derivatives as potent and selective Polo-like kinase (PLK) inhibitors. Bioorg Med Chem Lett 2009, 19:4673-4678.

20. Rheault TR, Donaldson KH, Badiang-Alberti JG, Davis-Ward RG, Andrews CW, Bambal R, Jackson JR, Cheung M: Heteroaryl-linked 5-(1H-benzimidazol-1yl)-2-thiophenecarboxamides: Potent inhibitors of polo-like kinase 1 (PLK1) with improved drug-like properties. Bioorg Med Chem Lett 2010, 20:4587-4592.

21. Kaup B, Bringer-Meyer S, Sahm H: Metabolic engineering of Escherichia coli: construction of an efficient biocatalyst for D-mannitol formation in a whole-cell biotransformation. Appl Microbiol Biotechnol 2004, 64:333-339.

22. Alphand V, Carrea G, Wohlgemuth R, Furstoss R, Woodley JM: Towards large-scale synthetic applications of Baeyer-Villiger monooxygenases. Trends Biotechnol 2003, 21:318-323.

23. Doig SD, Avenell PJ, Bird PA, Gallati P, Lander KS, Lye GJ, Wohlgemuth R, Woodley JM: Reactor operation and scale-up of whole cell Baeyer-Villiger catalyzed lactone synthesis. Biotechnol Prog 2002, 18:1039-1046.

doi:10.1186/1475-2859-11-7

Cite this article as: Mädje et al:: Host cell and expression engineering for development of an E. coli ketoreductase catalyst: Enhancement of formate dehydrogenase activity for regeneration of NADH. Microbial Cell Factories 2012 11:7. 